\title{
Propiedad precarizada y violencia en \\ los barrios antiguos
}

\author{
Horacio Gago Prialé
}

\section{Introducción}

En este artículo analizaremos la posible relación entre violencia y falta de derechos de propiedad en las zonas tugurizadas de los barrios antiguos urbanos. Nos ayudaremos con el concepto de energía traído de la física, según el cual la energía es cinética (en movimiento) o potencial (en reposo) y propondremos que la violencia es una forma de energía con similar ambivalencia. Expondremos que tanto la violencia potencial como la cinética se presentan con facilidad en situaciones socialmente deficitarias, y que la vida humana en un tugurio padece grandemente de este tipo de déficit.

En nuestra línea de argumentación tomaremos distancia de la consabida explicación «cultural» sobre el deterioro y ruina de los barrios antiguos o centros históricos, según la cual los vecinos actuales carecerían de comprensión sobre la dimensión histórica y el valor monumental de sus posesiones, prefiriendo vivir en estado de hacinamiento y descuido y que promoverían la tugurización y degradación de sus barrios para crear y medrar de focos de violencia y marginalidad. Por el contrario, sostendremos que ahí donde se redefina y masifique los derechos de propiedad en favor

* Horacio Gago Prialé (Huancayo, 1964) es abogado por la PUCP y doctor en Derecho por la Universidad Pontificia Comillas de Madrid - España. Profesor de la Maestría de Derecho con mención en Política Jurisdiccional de la PUCP. Es experto en estudios sobre derecho espontáneo y costumbre jurídica, informalidad y sistemas jurídicos. Trabaja como consultor del PNUD en el proyecto de desprecarización y capitalización de la propiedad urbana. Es autor de Sociedad espontánea y derecho en el Perú (Madrid: Civitas, 2000). 
de los vecinos, el capital social tenderá a incrementarse y con este también el respeto a la ley y a la seguridad. Y finalmente sustentaremos la idea de que un sistema normativo será capaz de contener incentivos para eliminar la violencia y cauterizar sus rezagos en los barrios antiguos tugurizados, siempre que los mecanismos del sistema de derechos de propiedad recojan y reflejen las buenas prácticas sociojurídicas.

\section{La violencia reclama coerción sí, pero mucho más que solo coerción}

En el escenario de un derecho conectado con la vida y necesidades sociales, creemos posible relacionar la idea de violencia y precarización de la propiedad en los barrios antiguos o centros históricos de ciudades como Lima y otras de América Latina. La idea del derecho como un sistema social, vital y dinámico de relaciones vinculantes, referido a una moral esencial, enlazado con el bien común, y cuya finalidad es la justicia concreta, abre muchas más puertas para la solución de los problemas de las personas, sociedades y países, que el limitado concepto del derecho positivo como mero conjunto de leyes. Es de agradecer que en los últimos años haya calado en el subconsciente de importante parte de la colectividad jurídica la idea de derecho como un sistema conectado con la vida social y por ende influido de su economía, historia, política, geografía, lengua, etcétera, superándose la concepción de un derecho puro y «descontaminado». La comprensión de que en general el conocimiento y la información (naturalmente también el conocimiento y la información jurídicos) se movilizan horizontalmente, abarcan muchos espacios a la vez, son transfronterizas, multidisciplinarías, se bifurcan y descentran repetidamente, es propia de estos tiempos y ha ido consolidándose en la misma medida que se devaluaba la idea de un derecho monocéntrico y de monopolio estatal ${ }^{1}$.

1 En nuestros países la creciente masificación del uso de las nuevas tecnologías de la información ha permitido nuevas formas de comunicación y de «relaciones vinculantes» (es decir de derecho) que enlazan cantidad de activos antes desperdigados, desconectados o invisibles en el inmenso mapa de la informalidad. Nuestro sector informal mismo no es más el de los años ochenta, cuando de lo que se trataba era de asegurar y perpetuar la posesión de espacios físicos para el desarrollo de micro emprendimientos. En los conglomerados informales de hoy la idea de valor se ha enriquecido con la idea de permanente dinámica. Lo que vale ahora es el rédito permanente y una veloz captura de la plusvalía, mas que la larga posesión de bienes o la tenencia de grandes stocks. 
El incremento de la eficacia coercitiva para hacer frente a los actos de violencia callejera o a las transgresiones de la ley, siempre fue y sigue siendo un clamor popular muy usual. Los humanos tendemos a la preservación (como cualquier especie) y por ello con velocidad reclamamos mayor coerción, es decir violencia legitimada, para quienes atentan contra la paz y estabilidad del «contrato social». Entre los ahorcamientos en el pasado de ladrones y revoltosos en las plazas, y la persecución a los autores de la invasión del mercado de Santa Anita de hoy, la única diferencia es el rating. En nuestra sociedad mediática, esos «ojos y oídos de la sociedad» que son la TV, radio y la prensa, organizan la diaria caza de brujas con un efectismo cada vez mayor, aprovechándose de la sensibilidad social contra los actos violentos. Probablemente sea legítimo e incluso ético, y por supuesto jurídico, denunciar y velar por condenas efectivas y severas a los matones que toman violentamente las carreteras, olvidando que son mineros, o a los traficantes que organizan violentamente invasiones de áreas públicas o privadas, o a los malandrines con carné universitario que violentamente quieren impedir la ejecución de obras en puentes y autopistas. Pero no por ello el derecho debe limitarse a contener este tipo de violencia.

Pero así como no todo acto violento agota el concepto de la violencia, tampoco la coerción agota, ni mucho menos, la idea del derecho. La relación entre ambos conceptos, violencia y derecho, es mucho más compleja que la mera relación causal entre una manifestación violenta y la necesidad de su cese y sanción. Quedarse en esto sería muy poco y muy pobre. El derecho no es solamente un sistema de gerenciamiento del aparato coercitivo sino un orden de generación de justicia particular cuya realización es asistida con herramientas (las instituciones formales e informales, leyes y costumbres ${ }^{2}$ ) que facilitan a los agentes del derecho (todos nosotros), la consecución de fines personales armonizados con el bien común. Ese orden actúa como una red de instrumentos normativos que facilitan las relaciones vinculantes, con al menos una mínima tendencia a la previsibilidad y usualmente organizadas para la libertad humana y bienestar. Esos instrumentos incluyen también sistemas de propiedad integrados por procedimientos, soportes de información y mecanismos de estandarización.

2 North, Douglass. Conferencia en Buenos Aires sobre las Instituciones. Buenos Aires: Revista Latinoamericana de Desarrollo Humano del Programa de las Naciones Unidas para el Desarrollo, 1998. 
El derecho no busca agregar más y mejor policía, sino hacer posible la vida social e individual de todos en libertad. De este modo, transgredir violentamente el orden jurídico, es tanto posible mediante actos que atenten contra el equilibrio social imprescindible que el sistema requiere (crímenes, subversión), cuanto impedir que los agentes del sistema acumulen violencia debido a condiciones de vida individual y social degradantes. De este modo la idea, más bien, va por el lado de que la violencia puede comprometer e implicar a todo el derecho como un orden jurídico y sistema de justa distribución de lo que a cada quien corresponde (justicia particular). En palabras más claras: la violencia existente en la sociedad puede afectar la labor de determinación o distribución de la «res justa» en muchos aspectos y no solo en el policial; y el Estado, actor crucial para el cuerpo social, debe hacerse presente no solamente en dicha faceta de modo eficiente para «restablecer violentamente y con legitimidad» el orden subvertido con «violencia ilegal», sino en todos los modos básicos que aseguren su misión, cual es armonizar el bien individual con el bien común.

Violencia no es solamente la manifestación del acto violento sino sus causas también. El Estado está implicado en todos los espacios sociales que brindan soporte a las personas en el cumplimiento de sus fines y búsqueda de prosperidad. Uno de esos espacios es el que nos interesa analizar: el del sistema de derechos de propiedad. Este sistema ha sido diseñado e instituido tanto para sostener actividades primarias (la morada digna) como para hacer posible una dimensión económica y financiera en favor de sus titulares. Supone un engranaje de factores interrelacionados (obligaciones de conservación del activo, claridad de los derechos posesorios, título actualizado, individualización del derecho, publicidad registral, etcétera) que deben guardar armonía. Si estos colisionan o actúan de espaldas entre sí durante períodos prolongados, lo que puede ocurrir es que aparezcan tanto la precarización de la propiedad ${ }^{3}$ como la tugurización de las viviendas, y

3 La precarización es entendida como el estado de severo deterioro de la capacidad de representación del derecho de propiedad de un activo inmobiliario, en términos económicos y financieros, causada por la dispersión cartular, la imposibilidad práctica de recomponer el tracto sucesivo y la desactualización registral del derecho de propiedad. El concepto fue definido por el Proyecto del PNUD, oficina del Perú, para la desprecarización y capitalización de la propiedad urbana. El autor es coordinador de dicho proyecto desde 2004. 
con ellas la generación de una larga cadena de entropía: languidecimiento del inmueble como activo, desconexión de zonas enteras de la ciudad con el sistema de inversiones, desaprovechamiento de barrios históricos y monumentales, recaudación municipal paupérrima, deterioro de fincas y de espacios públicos, ruina de casonas antiguas, hacinamiento humano, marginalidad, etcétera. Como vemos, este impacto negativo va mucho más allá de la esfera abstracta con la que típicamente se relaciona al sistema de propiedad y, por el contrario, se expresa en facetas muy concretas, y su relación con la pobreza es directa.

¿Está implicado el Estado en ello? Por supuesto que sí desde el momento en que la propiedad se asume como un derecho sometido a limitaciones y se manda por la propia Constitución que este derecho armonice con el bien común (artículo 70 de la Constitución peruana de 1993), encargándose a los gobiernos locales la tarea de que así sea. Por tal razón, las políticas de renovación urbana deben ser pensadas también como formas de enfrentar la violencia que se acumula en los tugurios.

\section{Violencia como una forma de energía. Violencia cinética y potencial}

Para una mejor comprensión de la relación violencia - derecho, la física trae información útil e interesante, de la cual extraemos dos ideas básicas que proponemos enseguida, no sin antes indicar que estamos actuando bajo la premisa de que toda decisión y acción humanas suponen el despliegue de algún tipo de energía, en alguna medida:

La primera ley de la termodinámica reza que la energía no se crea ni destruye, sino que solamente se transforma. Si entendemos que la violencia ilegal es una forma perniciosa de energía que afecta el cuerpo social, un sistema jurídico bien estructurado, en el sentido de adecuada y eficientemente entroncado con la realidad, podría no solo reprimirla sino reconducirla o convertirla en energía favorable al bien común. Por ejemplo, si el sistema jurídico pudiera reconocer la gravedad de la precarización de la propiedad en determinados conglomerados urbanos tugurizados, e identificar entre los colectivos sociales que moran por décadas en ellos en cuartuchos insalubres y callejones peligrosos, la rica gama de pautas de vinculación 
espontánea que en ellos existe y las regularidades jurídicas (normas consuetudinarias) sobre derechos posesorios que esos colectivos sociales cultivan, se haría mucho más sencilla la imprescindible redefinición de los derechos de propiedad, premisa sine qua non para cualquier renovación urbana sostenible. Es altamente probable que este reconocimiento transformaría la violencia existente en los tugurios en energía formativa de capital social, en sumo necesaria para la misma renovación urbana que todos (Estado, propietarios, vecinos, cooperación) dicen buscar. Esta primera idea es básica. La violencia no desaparece, solo se transforma en otro tipo de energía. El Estado debe estimular este tránsito.

La segunda idea básica también proviene de la física y está referida al hecho de que la violencia, como una forma de energía contra el cuerpo social, existe en estado manifiesto o de reposo, esto es, puede comportarse de modo actuante o permanecer en estado potencial (los sociólogos llamarían a esta última violencia estructural). En física se afirma que

[...] sea cual sea la forma de energía con la que estemos tratando, admite a su vez que se la clasifique en cinética y potencial: nacida en la descripción del comportamiento de la energía mecánica. Se considera energía potencial a aquella que no está provocando sus efectos en el presente, pero puede hacerlo en el futuro. En tanto que se considera cinética a la energía cuya acción o efecto, se encuentra en pleno desarrollo en el presente» ${ }^{4}$.

La violencia cinética sería la expresión culminante de un proceso de decisión extremado por las condiciones y exteriorizado en un acto violento (un crimen, una trasgresión violenta). La potencial se referiría a las condiciones que propician esa olla de presión presta a estallar. En ambos casos se evidencian la responsabilidad del derecho y del Estado nítidamente.

En resumen, dentro del cuerpo social y del sistema jurídico, la violencia sería una forma de energía enemiga del bien común bajo las dos formas en que existe, ya sea en movimiento o en reposo. Evidentemente, cuando los agentes llegan a exteriorizar violentamente una decisión transgresora (violencia cinética) resultan descargando mala energía sobre el cuerpo social

4 BARRAGÁN, Jorge. «Sobre la termodinámica de los sistemas físicos biológicos (I). El envejecimiento: ¿Una cuestión de geometría? Un modelo topológico de la biología». Artículo aparecido en la revista virtual de la Red Científica. Ciencia, Tecnología y Pensamiento, 2004. <http://www.redcientifica.com/doc/doc200403270001.html>. 
que este deberá asimilar y revertir. Pero es necesario advertir que la violencia cinética descargada fue antes potencial porque, como hemos visto, se trata de energía que preexiste bajo una forma acumulada. Lo deseable es transformarla tanto si está en reposo o en movimiento. Se aspira que el derecho y el Estado provean de condiciones para mudar este tipo de decisión y atraigan la misma energía para beneficiar a la sociedad con acciones que sumen al bien común.

\section{La violencia puede transformarse en otra forma de energía dependiendo de las condiciones y de cómo sea producido el derecho}

El cuerpo social está compuesto por personas y colectivos, desde la familia, la localidad, la ciudad, la región y eventualmente la nación. Las personas y los colectivos están dotados de facultades y protegidos por garantías para actuar en la sociedad (por lo menos en teoría). Y cuando las personas actúan lo hacen con un mínimo de autonomía dependiendo de la solidez del entramado institucional de garantías que exista en ese sistema. En ese cuerpo social los individuos y los grupos toman permanentemente decisiones o realizan acciones orientadas a satisfacer sus necesidades o aspiraciones. El punto es que cuando esas decisiones son vinculantes, o sea jurídicas, se genera necesariamente un despliegue de energía que compromete al cuerpo social al menos en un mínimo grado. Esto es así porque el derecho existe en función de la sociedad y no hay sistema jurídico sin esta («en la isla de Robinson» no se vive en un orden jurídico), de modo que las decisiones que sean vinculantes siempre requerirán de exteriorizarse, o sea de volcarse hacia fuera del sujeto de derecho y hacerse cognoscibles en el cuerpo social. Michel Villey subraya muy bien esto cuando defiende la tesis objetiva del derecho como el «to dikaion» aristotélico o el justo medio en la distribución o traslado de bienes exteriores para asignar lo que a cada quien corresponde 5 .

Entonces, la energía desplegada o que se manifiesta cuando se emprenden acciones o decisiones jurídicas, va a implicar inevitablemente un impacto en la sociedad. Esta va a quedar afectada como cuerpo social e implicada por cada una de las decisiones jurídicas de todos los agentes.

5 Viltey, Michel. Filosofía del Derecho. Barcelona: Editorial Scire Universitaria, 2003. Versión original: Philosophie du droit. Paris 1982. 
Así, deberá acoger esa energía desplegada para reorganizarla buscando guardar el conjunto, estimulando acciones que se conduzcan al bien común: pagar los impuestos, cumplir con las cláusulas de un contrato y generar valor en la economía; o reprimiéndola si responde a un acto de violencia ilegal que burla el orden y equilibrio social.

Resulta interesante ver cómo dependiendo de las condiciones y estructura de un sistema dado de derecho, la energía que despliegan las decisiones jurídicas de los agentes y las respuestas del Estado, va configurando mayor o menor espacio para la violencia. Mientras más eficiente y legítimo (en el sentido de inclusivo, participativo y arraigado en las prácticas jurídicas espontáneas) sea el proceso normativo que sustenta y retroalimenta al sistema, mayor posibilidad habrá para conducir la energía desplegada por los agentes hacia el bien común. Y lo contrario: cuando el sistema de principios jurídicos y normas sufre de serios disloques con la realidad, sea porque no la refleja adecuadamente o porque no actualiza sus esquemas de referencia con ella, la energía desplegada por la sociedad no encontrará instituciones oficiales que la acepten y reorganicen, con lo que el sistema remitirá toda ella, o gran parte, a los esquemas coercitivos, para castigar o tratar de punir estos enormes sectores de decisión jurídica de las personas y grupos. Como el sistema no cuenta entre sus estándares institucionales el tipo de decisiones de muchos de los agentes del cuerpo social (y no los tiene porque no los conoce, y no los conoce porque no los ha identificado ni querido hacerlo), los rechaza. De esta manera, por desconocimiento y falla del sistema en identificar y sistematizar las instituciones informales, las lee como ilegítimas y violentas, entonces las penaliza.

También resulta interesante cómo en este análisis de violencia y derecho se puede observar el funcionamiento de la comentada primera ley de la termodinámica por cuanto dependiendo de si el sistema jurídico es capaz de procesar las decisiones de los agentes y estimular el bien común, lo que podría haber sido rechazado y punido por desconocido, termina siendo reorganizado y acogido. De este modo un acto potencialmente visto como violento, rechazado y susceptible de persecución por el orden coercitivo, se convierte en uno necesario para el cuerpo social y se suma al bien común. De esa envergadura es la diferencia que puede producir en el progreso del cuerpo social y en la prosperidad de sus miembros que el sistema se halle más o menos entroncado con las realidades jurídicas espontáneas, con el derecho vivo. 
Hemos adelantado que siendo la violencia una forma de energía no podría crearse ni destruirse, solamente transformarse. Muy bien. Efectivamente, si el sistema jurídico es el adecuado y el proceso normativo legítimo y eficiente, entonces ese tránsito de la energía hacia fines plausibles, con buen y esperable impacto en el bien común, será posible en la misma proporción en la que la violencia ilegal dejará de manifestarse. La energía social no actuará como violencia sino que se expresará como capital social.

Precisamos: si hemos asumido que la violencia es una forma de energía presente en la sociedad entonces debemos continuar afirmando que la violencia puede ser cinética o potencial. Será cinética cuando se hace manifiesta a través de actos de exteriorización y potencial cuando se halle reposando. El punto crítico es descubrir cuándo y por qué, bajo qué condiciones y estimulada por qué motivos, la violencia en reposo o potencial se convierte en cinética, y bajo qué otras condiciones y estímulos esa energía podría conducirse a configurar capital social.

\section{Violencia y tugurios}

En la cadena de entropía que supone un sistema ineficiente de propiedad, la tugurización es el último y más patético eslabón. Su relación con la pobreza y la violencia es algo muy documentado. El Núcleo de Estudios sobre la Violencia de la Universidad de Sao Paulo (Brasil) ha estudiado el tipo de violencia generado en las favelas de las metrópolis brasileńas. El nivel de deterioro de la vida humana y social al que han llegado muchos de estos conglomerados urbanos (originados en la misma época que las invasiones y pueblos jóvenes de Lima y de hecho muy parecidas entre sí especialmente en las primeras etapas de estos asentamientos) podría decirse que ha institucionalizado un sistema de violencia potencial y cinética retroalimentado y sostenido, quizá irreversible.

En el análisis que realiza Nancy Cardia, de la Universidad de São Paulo, sobre la violencia en las favelas de la mayor metrópoli brasileña destacamos cuatro aspectos asimilables a los tugurios peruanos ${ }^{6}$ :

6 CARDIA, Nancy. "Globalisation and urban violence: the case of São Paulo». Núcleo de Estudos da Violência - Universidade de São Paulo, 2008. 
La tasa de homicidios es mayor en los lugares donde las casas se encuentran hacinadas, no cuentan con servicios de baño ni desagüe y es frecuente que las necesidades básicas se hallen superpuestas.

Ahí donde los jefes de familia no reciben un ingreso ejercen menos autoridad dentro de sus casas, viendo desafiada su condición de cabeza de familia por el resto de miembros de sus familias con frecuencia. Los más jóvenes van careciendo de modelos exitosos que guíen sus aspiraciones. Ello conduce a mayor tensión e incertidumbre en la casa, factores desencadenantes de la violencia. El alcohol y las drogas se convierten en ruta de escape a semejante estrés.

El desempleo prolongado manifestado en la presencia de hombres mayores en los espacios públicos durante el día laborable, siembra maledicencia y se posicionan los estereotipos sociales que dańan severamente la autoestima, todo lo que puede incrementar el uso de alcohol y la violencia familiar.

Mientras la vida avanza se convierte en más competitiva y estresante. Peor si la gente, en su lucha por sobrevivir, conduce a los jóvenes a la creencia de que no existe razón para soñar con un mejor futuro. Esto sea quizás lo más dañino de la vida en las favelas y el meollo de las causas de la violencia: cuando los jóvenes dejan de ver una salida de escape y sienten que no tienen nada que perder con practicar la violencia.

Un tugurio es un núcleo potencial y actual de violencia. Si bien en nuestras ciudades no se ha llegado a los extremos de las del Brasil, donde la actividad criminal ha sentado sus bases casi de modo irreversible llegando a sustituir en valores y reglas de comportamiento al mismo derecho espontáneo de la informalidad (caracterizado por una ética del trabajo), sus condiciones actuales en el Perú son propiciatorias del mismo fenómeno de degradación previo a la actuación violenta.

En los tugurios de las ciudades peruanas ${ }^{7}$, la persona humana carece de un espacio individual mínimo para su expresión como sujeto, los ambientes al interior de la vivienda deben soportar tres y más usos, se superponen

Programa de las Naciones Unidas para el Desarrollo (PNUD). Informe sobre tipologías de uso del espacio. Proyecto de Capitalización y Desprecarización de la Propiedad Urbana. Lima, marzo 2006. 
una y más carencias en una cadena de déficit social inacabable. Simultáneamente, el núcleo social inmediato de referencia se encuentra deteriorado, el jefe de familia no proyecta la imagen de éxito y modélica esperable, hay presencia de drogas y de alcoholismo, los indicadores de desarrollo humano son bajos o muy bajos debido al deterioro y ruina de las estructuras e instalaciones del tugurio, y se carece en general de un entorno amigable. En esta realidad, la violencia potencial se hace cinética todo el tiempo, de a pocos, al ritmo del derrumbamiento físico de la casona o del callejón, pared por pared, puerta por puerta, cornisa por cornisa, balcón por balcón; o abruptamente, cuando la amenaza del desalojo se materializa y aparece el secretario de juzgado con la policía para lanzar a la gente de sus casas, provocando indignación y otras maneras de reacción violenta, o al desaparecer toda posibilidad de alcanzar un empleo temporal por la mala fama del barrio. Las condiciones acumulan violencia todos los días, como si fuera una represa de capacidad inagotable. Este depósito de violencia se resquebraja permanente e indeteniblemente y la energía que expulsa con violencia impacta en el resto de familias, en el barrio y distrito entero y, como hemos visto, solo recibe del Estado una respuesta en términos de coerción. Esta misma (la coerción) no hace sino atizar la violencia potencial acumulada.

\section{La tugurización como consecuencia de un problema mayor: la precarización de la propiedad}

En los tugurios se atiza diariamente decisiones transgresoras y aparece la violencia individual y colectiva en medio de condiciones que no hacen sino empujar esta tendencia. El deterioro no se detiene y la precarización de los derechos de propiedad se encuentra en la base del problema. Es su causa.

Los viejos predios de los barrios antiguos e históricos se arruinan sin freno, sus dueños, o lo que queda de ellos son apenas portadores de pequeńas alícuotas de un título fragmentado y atomizado, a quienes poco o nada interesa la conservación de la casona. Es probable que ni siquiera estos herederos sigan vivos o que estándolo conozcan a sus copropietarios o tengan relaciones lo suficientemente sostenibles con ellos como para alcanzar acuerdos de transferencia o planes serios de renovación. De hecho, la mayoría de herederos ni siquiera ha visitado el predio en los últimos ańos, casi ninguno de ellos ha vivido en el barrio ni menos hecho amigos 
en él. Ni siquiera aspiran a renovar la casona o quinta para cobrar mejores alquileres; asumen únicamente que se trata de un barrio perdido, un valor deteriorado, un predio ubicado en el infierno. Como mucho, anhelan que algún día el inmueble termine de derrumbarse para que las familias que viven en él tengan que dejarlo inevitablemente y ellos puedan, quizá, recuperarlo para venderlo a pedazos.

La casona y el callejón aparecen en el registro como la unidad que alguna vez fueron, no como la vivienda multifamiliar que son. Su referencia registral data de cuando se trataba de casas huerta donde moraba una sola familia, de las acomodadas de aquellos tiempos (siglo XIX, comienzos del $\mathrm{XX}$ ); o como mucho, contiene algún agregado referido a la conversión sufrida por la huerta jardín, en la parte del fondo de la casona, donde algún antiguo dueño decidió construir una batería de cuartos pequeños, con un único baño al fondo, para que los habitaran inquilinos temporales, dedicados a servicios menores, sacando provecho de la ubicación cada vez mas central del barrio. Ese dato registral no da cuenta de la ruina existente por todas partes del predio ni el derrumbamiento de las paredes o de los pisos de la segunda planta. Tampoco del colapso de las cornisas ni la humedad de los patios.

$\mathrm{Al}$ morir el cabeza de estirpe ese título nunca se individualizó. Como mucho, hubo intentos de subdivisión que no se concretaron. Los papeleos excesivos, las peleas internas, «los errores formales» frecuentes en alguna escritura o partida registral que había que subsanar con gran costo, y el desinterés general abonaron para que se eternizara la indivisión del título. El resultado de esta suma de descuidos voluntarios e involuntarios fue y sigue siendo la muerte económica del título. Su precarización. Su ineficacia en términos prácticos.

En la aparición de la enfermedad jurídica llamada precarización, la gran responsabilidad recae en un sistema legal que no ha creado los incentivos para que lo transitorio sea eso, temporal, y para que la copropiedad no se convierta, como ocurre en la casi totalidad de casonas tugurizadas, en una condición permanente que ha atado y sigue atando de tal modo al derecho de propiedad hasta asfixiarlo completamente.

Los herederos, como es natural, mueren a su vez. Sus hijos viven fuera del país o pierden relación con sus parientes, así como va desapareciendo 
en ellos el rastro consciente sobre la existencia de una alícuota que les pertenece sobre un predio en algún rincón de un barrio tugurizado. Mientras tanto las muchas familias que lo habitan ven cómo aquel se cae todos los días a pedazos.

Esto se llama violencia potencial.

Al sobrevenir la precarización, cosa que ocurre de a pocos, van desapareciendo los signos claros que distinguen una relación fluida propietario - inquilino. Para comenzar, la idea de propietario en estos casos muy pocas veces remite a la idea de un "propietario individualizado", sino a la de un abanico de herederos que como hemos visto no se ponen de acuerdo (ni se conocen muchas veces) en aspectos legales básicos sobre la propiedad y registro de la finca, actuando con igual o menor diligencia en cuanto a sus responsabilidades como arrendadores. Sin siquiera documentar el nombre completo de sus inquilinos, menos lo hacen con los plazos de estos contratos, descuidando incluso la cobranza de la renta. Como mucho, uno de los numerosos herederos, por supuesto sin la autorización de los otros, suele deambular periódicamente por los cuartos del callejón, cobrando la mensualidad, o encarga esta labor a un cobrador sin poderes suficientes ni contabilidad clara. El tiempo pasa y la casa se sigue cayendo. Nadie, ni siquiera el heredero cobrador, ni mucho menos los demás que aparecen en el registro, emprenden el trabajo de conservación.

En su condición de inquilinos, las familias que viven en el predio por décadas (nacieron ahí) y que para este momento ya llegaron a ser decenas dentro de la casona o callejón, tampoco pueden encargarse de conservar o renovar el predio, responsabilidad exclusiva del dueño. Cuando lo han intentado la municipalidad les multó e impidió las obras, limitándose apenas a realizar apuntalamientos precarios de las paredes para evitar se desplomen. Se preocupan por la inminente desgracia todos los días, eligen sus dirigentes para que los representen ante el municipio, se reúnen permanentemente y hablan sobre la posibilidad de comprar la vieja casona. Piensan en ahorrar lo necesario, pero cuando indagan en los registros y descubren que los dueños son como un racimo de uvas, con ramas que se forman y bifurcan una y otra vez debido a que muchos de ellos van falleciendo y con ello fragmentando y fragmentando el título, se convencen de que tal empresa es un imposible. 
En resumen, la precarización de la propiedad equivale en la práctica a la inexistencia de propiedad. Se trata de un estado de deterioro del título tan severo que se refleja o impacta en el activo de modo tal que ni siquiera la casa puede cumplir con su función primaria, cual es servir de morada digna para las familias que lo habitan. Ese deterioro conduce inevitablemente a la tugurización, y como hemos visto, a la violencia como consecuencia de ello.

La tugurización es la consecuencia de un problema jurídico llamado precarización de la propiedad y sus manifestaciones de violencia también lo son de un modo indirecto. Solucionarla no va a ser posible sin la activación de los mecanismos jurídicos de los que está dotado un eficiente sistema de propiedad, tarea directamente de responsabilidad del Estado, tanto en su faceta de gobierno local cuanto central. Y si el derecho positivo carece de un eficiente sistema de propiedad no queda otra solución que crearlo, para lo cual será necesario partir desde el mismo mandato constitucional según el cual la propiedad se ejerce en armonía con el bien común y dentro de los límites de la ley.

¿Es capaz el Estado peruano de dotar de eficiencia al sistema de propiedad? ¿Es posible integrar todos los eslabones de la cadena de la propiedad: títulos, registro, municipalidad, propietarios, moradores, sistema financiero, en un sistema interactuante? No cabe respuesta negativa a esta pregunta.

\section{El capital social que existe en medio de los tugurios}

Cuando las Naciones Unidas proclamaron en los albores del año 2000, entre las metas del milenio la destugurización de cien millones de personas antes del año 2020, para muchos observadores quedó claro el interés del sistema internacional por proveer de atención a uno de los problemas más acuciosos de la vida humana en las ciudades ${ }^{8}$. Esta decisión fue inscrita en el gran marco de lucha contra la pobreza y de generación de herramientas

8 UN - Habitat calcula que actualmente por lo menos mil millones de seres humanos en todo el planeta viven en barrios precarios y que para 2020 lo harán 1.500 millones. La meta de cien millones de personas destugurizadas propugnada por las Naciones Unidas es, entonces, diminuta frente al problema. Sin embargo el hecho que el problema se haya inscrito en la agenda de acción internacional es un acontecimiento de primer plano. La conciencia del potencial nivel de degradación y violencia que existe en estas zonas urbanas ha quedado muy clara. 
efectivas de inclusión social. Se trata de masificar los beneficios de la modernidad entre todos los sectores de la sociedad, los tugurios incluidos.

Al lanzar esta proclamación las Naciones Unidas, posiblemente han tenido presente los extremos a los que puede llegar la exclusión social y la violencia que se contiene en los tugurios. En América Latina, las ciudades brasileñas, nuevamente, son las que brindan la imagen más radical. Junto al problema de las favelas cuya asimilación social, cultural, jurídica y económica por un sistema sustituto de crimen organizado, supone el mayor desafío al sistema de derecho que se haya conocido hasta ahora, se encuentra el abandono de los centros históricos de las ciudades emblemáticas como Sao Paulo, Río o Salvador. En estos se presenta el fenómeno de la re nomadización de muchos de los colectivos excluidos de todo. La imagen de ejércitos de familias aposentadas en espacios públicos (parques, jardines) deambulando y vagando, medrando y mendigando, al lado de edificios destartalados, vacíos por dentro y cerrados a cal y canto por fuera, es reveladora de los extremos a los que el problema puede haber llegado y también de la capacidad humana de sobrevivencia. El capital social en estos casos parece haber desaparecido del todo.

En el Perú no se ha llegado a tanto. Todavía. La eliminación de los tugurios en nuestro país no debe equivaler a la erradicación de la vida humana ni al reasentamiento de sus colectivos sociales, ni mucho menos al desalojo violento del 1,8 millones de familias peruanas que moran en estas condiciones ${ }^{9}$. En los barrios antiguos de las ciudades peruanas la vida bajo las extremas condiciones de un tugurio no ha hecho desaparecer, pese a su violencia, la trama de derecho espontáneo, costumbres y consensos sociales que brindan dinámica a la rutina de las familias que moran con precariedad en estas viviendas. Los males son muchos pero la capacidad de hacerles frente, con imaginación, solidaridad y esperanza, son también característica de la vida en los tugurios.

Son en los barrios antiguos de donde proceden las mejores manifestaciones de la tradición popular, y desde los cuales se proyecta las trazas más características de las costumbres ancestrales a otras zonas de la ciudad.

9 Cifras del Instituto Nacional de Estadística e Informática (INEI) indican que en Lima y las 42 ciudades peruanas con más de cien mil habitantes las viviendas consideradas como inhabitables alcanzan un número mayor a 1,8 millones. 
Lima, por ejemplo, vive muy orgullosa de sus costumbres, arte culinario y religiosidad. Podría parecer una paradoja pero no lo es. Las miles de familias que viven en las casas ruinosas son las primeras en destinar tiempo, recursos, atención y cultivo de estas expresiones culturales con las que se relaciona tan directamente el capital social. El calendario de festividades religiosas y la celebrada gastronomía, ambas con denominación de origen en los barrios antiguos, son dos claros ejemplos de este concierto de voluntades, tradición oral, amor a lo propio y respeto por una tradición antigua, columnas que sostienen cualquier sistema de vida humana que cuente con el preciado capital social.

La vida social en los barrios antiguos tugurizados a causa de la precarización, no ha desaparecido. Tampoco su derecho espontáneo. Este consiste en un sinnúmero de normas consuetudinarias que solventan los derechos posesorios y maximizan las ventajas de la ubicación céntrica de sus barrios, dotada de servicios públicos gracias a ella. Su nivel de asociacionismo es alto, su capacidad de comprensión sobre la potencialidad de un centro histórico también lo es. La posibilidad, en fin, de generar compromisos en el orden de la renovación urbana, existe y ha sido documentada.

Queda saber si el Estado podrá hacer frente a la ineficiencia de su sistema de propiedad, y corregirla. Esto supone una labor compleja que involucra en primer lugar a la misma gente que mora y padece de este nivel de violencia, pero en segundo lugar y muy cercanamente, a la capacidad pública para crear un sistema de propiedad eficiente que estimule las transferencias de propiedad, empodere a los vecinos, genere compromisos concretos con ellos y restablezca la vida económica de esos derechos de propiedad precarizados. Solo así la violencia potencial y la cinética cederán en los barrios antiguos, por cuanto, los derechos de propiedad tienen la virtud de eliminar energía violenta y transformarla en esquemas de maximización de bienestar. Ese es el cometido. Violencia y capital social se repelen. Violencia y Estado de derecho también. 